\title{
PADRÃO DE QUALIDADE DA SILAGEM DE SORGO (SORGHUM BICOLOR L. MOENCH) ASSOCIADO AO NEEM (AZADIRACHTA INDICA)
}

\author{
M. M. DE F. SOARES ${ }^{1}$, C. M. S. DE SOUZA ${ }^{2}$, B. N. RODRIGUES ${ }^{3}$, F. DA C. R. TERCEIRO ${ }^{4}$, H. F. M. BARRETO ${ }^{5}$, P. P. \\ C. DE JESUS ${ }^{6}$ \\ Instituto Federal de Educação, Ciência e Tecnologia do Rio Grande de Norte ${ }^{2,5}$ Universidade Federal Rural do \\ Semi-Árido 1, 3, 4, 6 \\ ORCID ID: https://orcid.org/0000-0003-2693-2976 ${ }^{1}$ \\ marianafreittas@outlook.com.br ${ }^{1}$
}

Submetido 07/05/2020 - Aceito 16/10/2020

DOI: $10.15628 /$ holos.2020.10073

\section{RESUMO}

O presente estudo foi conduzido com o objetivo de avaliar as características de silagem confeccionadas com forragem de sorgo associada as folhas do neem em diferentes níveis de substituição. O experimento foi realizado no IFRN - Campus Apodi. O sorgo utilizado foi da variedade BRS Ponta Negra consorciado com a forragem do neem (folhas e pecíolos). Foram confeccionados 48 minissilos, preenchidos com as matérias-primas previamente trituradas, sendo abertos aos 28 e 35 dias após a ensilagem, distribuídos em um delineamento inteiramente casualizado com os cinco níveis de substituição das folhas do neem $(0 ; 25 ; 50 ; 75$ e $100 \%)$ e um do neem com associação de melaço $(100 \%+$ $\mathrm{M})$, sendo 4 repetições. Analisando os resultados obtidos para matéria seca (MS) tem-se que a mesma sofreu influência a medida que aumentava os níveis de substituição. $O$ teor de proteína bruta (PB) aumentou de acordo com o aumento do nível de substituição do sorgo pelo neem. Quanto ao teor de fibra insolúvel em detergente neutro (FDN) percebe que os níveis de substituição 50; 75 e 100\% de neem, além dos 100\% neem + melaço, aos 28 dias de armazenamento não diferiram estatisticamente. As temperaturas das silagens foram influenciadas pelo nível de substituição de sorgo pelo neem aos 28 dias. Para o $\mathrm{pH}$ não foi observado diferença significativa evidenciando uma boa qualidade de silagem se mantendo na média de 3,51 a 4,15. Portanto, a substituição da forragem de sorgo pelo neem deve ser utilizada até o nível de $25 \%$, assim como se pode ensilar o neem associado a $5 \%$ de melaço, aos 35 dias de armazenamento, pois a composição química foi considerada satisfatória, configurando-se como uma alternativa que pode ser usada na alimentação dos ruminantes.

PALAVRAS-CHAVE: Composição química, Ensilagem, Melaço, Nutrição de Ruminantes, Substituição.

\section{QUALITY STANDARD OF SORGO SILAGE (Sorghum bicolor L. Moench) ASSOCIATED WITH NEEM (Azadirachta indica)}

\begin{abstract}
The present study was conducted to evaluate the silage characteristics of sorghum forage associated with neem leaves at different levels of substitution. The experiment was carried out at IFRN - Campus Apodi. The sorghum used was from the BRS Ponta Negra variety. One hundred and twenty minisils were prepared, filled with previously crushed raw materials, and opened at 28 and 35 after silage, distributed in a completely randomized design with the five levels of neem leaf replacement $(0 \%, 25 \%$, $50 \%, 75 \%$ and $100 \%$ ) and one of the neem with molasses association $(100 \%+M)$, with 4 repetitions. Analyzing the results obtained for $\mathrm{MS}$, it has been influenced by the increase in substitution levels. The CP content increased with increasing level of sorghum substitution by neem. Regarding the NDF content, it is noticed that the
\end{abstract}

replacement levels $50 \%, 75 \%$ and $100 \%$ of neem, in addition to $100 \%$ neem + molasses (46.69), at 28 days of storage did not differ statistically. Silage temperatures were influenced by the level of sorghum substitution by neem at 28 days. The $\mathrm{pH}$, was not observed significant difference, evidencing a good quality of silage keeping the average of 3.51 to 4.15 . Therefore, the replacement of sorghum forage by neem should be used up to $25 \%$ level, as well as the neem associated with $5 \%$ molasses at 35 days of storage, because the chemical composition was considered satisfactory, configuring it. as an alternative that can be used to feed ruminants.

KEYWORDS: Chemical Composition, Forage, Fermentation, Ruminant Nutrition, Substitution. 


\section{INTRODUÇÃO}

A estacionalidade na produção de forragem na região semiárida do Nordeste, aliada a predominância no uso da vegetação de caatinga e dos sistemas extensivo e semi-intensivo de produção, faz com que a viabilidade das atividades pecuárias dependa do planejamento de estratégias de produção e armazenamento de volumosos, uma vez que no período de estiagem há escassez de forragem.

O armazenamento de forragem através da ensilagem é uma alternativa bem difundida para suprir a deficiência de alimento no período de escassez e as plantas forrageiras mais utilizadas para a confecção de silagem é o milho (Zea mays) e o sorgo (Sorghum bicolor) (Stella et al., 2016), tendo esta, alto valor nutritivo e bom redimento produtivo, além de boa aceitabilidade pelos animais (Neumann et al., 2004).

Além do cultivo dessas plantas forrageiras, muitas alternativas presentes no semiárido têm sido utilizadas de maneira empírica por produtores, como por exemplo o neem (Azadirachta indica A. Juss. Meliaceae) ou Nim, que está sendo cada vez mais utilizada em sombreamentos pela sua capacidade de adaptação as condições do semiárido. Fonseca et al. (2019) descrevem que dessa planta se origina diversos produtos fitoterápicos de uso na agricultura e pecuária, tendo destaque para o uso no contorle de helmintos gastrintestinais.

O uso do neem como planta forrageira na Ásia e África foi relatado por Adjorlolo et al. (2016) que também descreveram a adaptabilidade dos pequenos ruminantes ao sabor amargo da planta. No Brasil, observa-se que alguns produtores nordestinos fazem o uso das folhas da planta como alternativa alimentar para os períodos de escassez alimentar, uma vez que a planta permanece verde durante todo o ano, contudo, os estudos em relação a composição nutricional dessa planta no Brasil são escassos.

Com isso, o presente estudo tem por objetivo avaliar as características de silagem confeccionadas com forragem de sorgo associada as folhas de neem em diferentes níveis de substituição.

\section{REVISÃO BIBLIOGRÁFICA}

\subsection{Sorgo forrageiro}

O sorgo forrageiro (Sorghum bicolor L. moench), planta originária da África pertencente a família das gramíneas, é considerado uma planta forrageira de boa resistência a seca, isso porque possui metabolismo fotossintético $\mathrm{C} 4 \mathrm{com}$ alta produção de fotoassimilados e um grande acúmulo de matéria seca (Santos et al., 2015). Apresenta, ainda, segundo Elias et al. (2016), a capacidade de rebrota, tolerância ao estresse hídrico e persistência a altas temperaturas do ar, o que confere ao sorgo a capacidade de produção em condições de limitado suprimento de água e, consequentemente, permite que ele se estabeleça em áreas aonde o milho não apresenta desempenho satisfatório. 
O sorgo é uma das plantas forrageiras mais difundida no Brasil, devido a sua facilidade de plantio, manejo, colheita e armazenamento, possuindo diversos grupos de cultivares, com alto valor nutritivo e alta concentração de carboidratos solúveis, em que justificam o potencial dessa planta para alimentação animal (Moura et al., 2016), principalmente nas regiões semiáridas do Nordeste Brasileiro, com níveis de proteína bruta (PB) entre $8 \%$ e 15\% e com os nutrientes digestíveis totais (NDT) entre $60 \%$ e $70 \%$ (Martini et al., 2019) quando utilizada in natura. Oliveira et al. (2010) encontraram valores da silagem de sorgo com 24,1\% para a matéria seca e 6,1\% para a proteína bruta, comprovando sua proximidade nutricional com a silagem de milho (27,3\% MS e 7,2\% PB).

\subsection{Neem (Azadirachta indica A. Juss.)}

O neem (Azadirachta indica A. Juss.) é uma espécie arbórea da família Meliaceae, tem origem Indiana e bastante utilizada com diversas finalidades, sendo atualmente cultivado em vários países da África, Austrália e América latina (Soares Filho et al., 2015).

A planta tem melhor adaptação em regiões tropicais e subtropicais, possui um porte de aproximadamente 15 a $20 \mathrm{~m}$ de altura, tronco semi-ereto a ereto de 20 a $80 \mathrm{~cm}$ de diâmetro, além de uma copa com diâmetro entre 8 a 12 metros. A idade em que a planta geralmente inicia a produção de frutos é de 3 a 5 anos após o plantio, com a produção podendo superar $25 \mathrm{~kg} / \mathrm{planta}$ após cinco anos (Mossini \& Kemmelmeier, 2005). Devido a essas características, a árvore do neem foi disseminado rapidamente no semiárido do Nordeste brasileiro, sendo atualmente muito usado na arborização de ruas, praças, parques e jardins (Azevedo et al., 2015).

Quanto ao seu uso na alimentação de animais, pouco são os estudos relacionados, havendo alguns fazendo uso da torta do neem, em contrapartida, são inexistentes as avaliações utilizando as folhas da planta. Mossini e Kemmelmeier (2005), afirmam que o uso da torta de neem tem apresentado resultados satisfatórios do ponto de vista econômico, sem causar danos a sáude do animal.

Estudos relatados por Musalia (2000), indicam que o uso da torta da semente de neem tratada com ureia em substituição a torta de amendoim na alimentação de ovelhas é uma excelente fonte proteica, com resultados positivos em relação ao ganho de peso, economia e segurança, entretanto, pode ocorrer formação de microcálculos nos rins.

As folhas do neem apresenta cerca de $13,42 \%$ de proteina bruta, $20,11 \%$ de fibra bruta e $5,17 \%$ de gorduras totais sendo seu caule um material com considerável presença de tanino além de expressivos teores de lipídeos totais (Atangwho et al., 2009).

\subsection{A silagem e suas características físicas}

A conservação de forragem, através da silagem, é uma estratégia que desempenha um papel fundamental na garantia da disponibilidade de volumoso de qualidade durante todo o ano, porém, faz-se necessário a seleção de cultivares mais adequados para essa técnica, afim de que se torne um produto de excelente qualidade (Lima-Orozco et al., 2013). 
A qualidade da silagem é influenciada por diversos fatores, sendo o teor de matéria seca da planta aquele que mais influencia os padrões de fermentação e, consequentemente, sua qualidade final, porém, o ter de matéria seca pode sofre variações de acordo com a idade de corte da planta, sendo recomendado que ela esteja entre 30 e 35\% para que ocorra uma compactação adequada e uma boa fermentação (Jobim et al., 2007).

A redução do pH no processo fermentativo a um patamar entre 3,8 e 4,2 está relacionada à conservação do material ensilado, além de diminuir a produção de amônia (McDonald, 1981) e o crescimento de micro-organismos anaeróbicos indesejáveis (Muck \& Bolsen, 1991).

A temperatura, considerada fator físico importante e, que, juntamente com o pH, é utilizada para determinar a qualidade da silagem, promovem melhor estabilização do processo fermentativo, onde a temperatura ideal da silagem deve chegar próxima a temperatura ambiente, caso contrário, se sugere que houve respiração oxidativa realizada por fungos e bolores. Segundo Greenhill (1964), constatou que após fechamento imediato do silo, à temperatura de $25^{\circ} \mathrm{C}$, demorou 5 horas para ocorrer a lise celular, sendo que em $40^{\circ} \mathrm{C}$ levou apenas 2 horas para a mesma acontecer, atribuindo tal fato ao aumento da taxa de respiração.

\section{METODOLOGIA}

O experimento foi conduzido no Instituto Federal de Educação, Ciência e Tecnologia do Rio Grande do Norte (IFRN) - Campus Apodi. O sorgo utilizado para produção da silagem foi da variedade BRS Ponta Negra ao qual foi cultivado segundo orientações de Lima et al. (2006) e a colheita mecânica foi realizada a partir do momento em que a forragem atingiu teores de matéria seca entre 30 e 35\%, considerados por McDonald (1981) adequados para o início do processo de ensilagem.

A forragem do neem foi coletada in natura em plantas aleatórias já adultas nas dependências do IFRN - Campus Apodi, sendo recolhidas apenas as partes mais tenras da planta, que correspondeu às folhas e pecíolos. O melaço utilizado foi proveniente de uma casa agropecuária da região, em que foi diluído, antes da inclusão na forragem, numa relação de 1 litro de água para três quilogramas de melaço e incluído numa proporção de $5 \%$ do material ensilado.

Foram confeccionados 48 minissilos experimentais, com tubos PVC, medindo $50 \mathrm{~cm}$ de altura e $10 \mathrm{~cm}$ de diâmetro, sendo adicionado o equivalente a $10 \mathrm{~cm}$ de areia para recuperação dos efluentes. Os minissilos foram preenchidos com as matérias-primas previamente trituradas e homogeneizadas, sendo compactadas com o auxílio de um soquete de madeira, procurando manter uma densidade próxima a $600 \mathrm{~kg} / \mathrm{m}^{3}$, e vedados utilizando lona plásticas fixadas com o auxílio de liga de borracha.

Os minissilos foram distribuídos em um delineamento experimental inteiramente casualizado, com cinco níveis de substituição da forragem do sorgo pela do neem $(0 ; 25 ; 50 ; 75$ e $100 \%)$, além da associação apenas do neem com o melaço $(100 \%+M)$, dois tempos de abertura ( 28 e 35 dias) após a ensilagem e quatro repetições, sendo submetidos ao esquema de parcelas subdivididas, onde os tratamentos foram alocados nas parcelas e os tempos de abertura nas subparcelas.

Alíquotas de aproximadamente $300 \mathrm{~g}$ foram coletadas, do sorgo e do neem, antes da 
ensilagem (Tabela 1), assim como dos silos no momento da abertura para a realização posterior das análises físico-químicas. As amostras foram acondicionadas em sacos plásticos vedados, identificados e armazenados a $-10^{\circ} \mathrm{C}$.

As análises físico-químicas foram realizadas no Laboratório de Nutrição Animal do IFRN Campus Apodi, onde o material foi pré-seco a $65^{\circ} \mathrm{C}$ durante 3 dias, triturado em moinho tipo willey, para determinação dos teores de matéria seca (MS), proteína bruta (PB), pelo método de Kjeldhal, fibra em detergente neutro (FDN) e fibra em detergente ácido (FDA), de acordo com a metodologia descrita por Silva e Queiroz (2009). A fração da lignina foi obtida a partir do resíduo da análise do FDA, pelo uso do método Klason, descrito por Mizubuti et al. (2009).

Tabela 1: Composição química do material a ser ensilado com base nos níveis de substituição da forragem de sorgo pela do neem.

\begin{tabular}{|c|c|c|c|c|c|c|}
\hline \multirow[b]{2}{*}{ Variáveis (g.100g-1) } & \multicolumn{6}{|c|}{ Níveis de substituição da forragem de sorgo pela do neem } \\
\hline & $0 \%$ & $25 \%$ & $50 \%$ & $75 \%$ & $100 \%$ & $\begin{array}{l}100 \%+ \\
\text { melaço }\end{array}$ \\
\hline Matéria Seca & 26,62 & 35,11 & 33,40 & 40,48 & 40,63 & 35,46 \\
\hline Proteína Bruta & 4,77 & 8,81 & 10,42 & 8,97 & 11,68 & 10,68 \\
\hline Fibra insolúvel em detergente neutro & 63,37 & 54,30 & 51,20 & 53,34 & 47,10 & 49,04 \\
\hline Fibra insolúvel em detergente ácido & 39,04 & 39,10 & 41,50 & 38,42 & 35,32 & 40,67 \\
\hline Lignina & 5,96 & 15,17 & 16,73 & 23,75 & 18,34 & 21,14 \\
\hline
\end{tabular}

No momento da abertura de cada minissilo foi verificado a temperatura com o auxílio de um termômetro digital, cujo sensor introduzido no centro da massa de forragem, bem como foram coletadas alíquotas para determinação do $\mathrm{pH}$, sendo acondicionadas em sacos plásticos, identificadas e armazenadas a $-10^{\circ} \mathrm{C}$ para posterior análise, cuja metodologia utilizada está descrita em Silva e Queiroz (2002).

Os resultados foram submetidos à análise de variância e teste de regressão por meio de análises de dados do software SAS (Statistical Analysis System, 1990).

\section{RESULTADOS E DISCUSSÃO}

Ao avaliar o teor de matéria seca (MS) encontrado nas silagens (Tabela 2), foi possível perceber que a mesma sofreu influência à medida que aumentaram os níveis de substituição da forragem de sorgo pela do neem aos 28 e 35 dias de armazenamento. A MS é a porção em que estão contidos todos os nutrientes e é através dela que se pode comparar o teor nutricional de dois ou mais alimentos, em que baixas taxas de MS podem favorecer o desenvolvimento de bactérias do gênero Clostridium e resultar em perda de nutrientes na compactação (McDonald et al., 1991). Porém, altas taxas de matéria seca causam problemas na compactação e prejudicam a anaerobiose e a diminuição do $\mathrm{pH}$, com perdas no material ensilado. Além disso, em ambos os casos pode haver possível redução no consumo dos animais (Borba et al., 2012). 
Tabela 2: Teores de matéria seca $\left(\mathrm{g} .100 \mathrm{~g}^{-1}\right)$ das silagens confeccionadas substituindo a forragem do sorgo pela do neem aos 28 e 35 dias de armazenamento.

\begin{tabular}{|c|c|c|c|c|c|c|c|}
\hline \multirow{2}{*}{$\begin{array}{c}\text { Dias de } \\
\text { armazenamento }\end{array}$} & \multicolumn{6}{|c|}{ Níveis de substituição da forragem de sorgo pela do neem } & \multirow{2}{*}{ Médias } \\
\hline & $0 \%$ & $25 \%$ & $50 \%$ & $75 \%$ & $100 \%$ & $100 \%+M$ & \\
\hline 28 dias & $28,77 a A$ & $30,23 b A$ & $34,88 \mathrm{cA}$ & $38,08 \mathrm{~dB}$ & $39,52 f A$ & $39,32 \mathrm{eB}$ & 35,13 \\
\hline 35 dias & $30,52 \mathrm{aB}$ & $32,21 \mathrm{bB}$ & $36,49 \mathrm{~dB}$ & $37,93 e A$ & $43,15 \mathrm{fB}$ & $34,93 c A$ & 35,87 \\
\hline Médias & 29,64 & 31,22 & 35,69 & 38,00 & 41,33 & 37,13 & \\
\hline CV (\%) & \multicolumn{7}{|c|}{0,11} \\
\hline
\end{tabular}

*Médias seguidas pela mesma letra minúscula na linha e maiúscula na coluna não diferem entre si pelo teste de Scott-Knott, a $1 \%$ de probabilidade

Legenda: $0 \%$ = silagem com $100 \%$ de sorgo e $0 \%$ de neem; $25 \%$ = silagem com $75 \%$ de sorgo e $25 \%$ de neem; $50 \%$ = silagem com $50 \%$ de sorgo e $50 \%$ de neem; $75 \%$ = silagem com $25 \%$ de sorgo e $75 \%$ de neem; $100 \%=$ silagem com $0 \%$ de sorgo e $100 \%$ de neem e $100 \%+M=$ silagem com $0 \%$ de sorgo e $100 \%$ de neem + melaço.

Analisando os resultados obtidos para MS nesse estudo, tem-se que os níveis mais adequados estão contidos entre os níveis de substituição de $25 \%\left(30,23 \mathrm{~g} \cdot 100 \mathrm{~g}^{-1}\right)$ e $50 \%$ de neem $\left(34,88 \mathrm{~g} \cdot 100 \mathrm{~g}^{-1}\right)$, aos 28 dias de armazenamento, e entre os níveis de $0 \%\left(30,52 \mathrm{~g} \cdot 100 \mathrm{~g}^{-1}\right)$ e $25 \%$ de neem $\left(32,21 \mathrm{~g} \cdot 100^{-1}\right)$, aos 35 dias de armazenamento. Estes valores podem ter sido influenciados pelo teor de MS da planta, que favorece no processo de ensilagem, visto que para o processo fermentativo ocorrer de forma satisfatória, o teor de matéria seca da forragem deve estar por volta de $30,0 \mathrm{~g} \cdot 100^{-1}$ (Jobim et al., 2007).

Observa-se ainda que a adição de melaço à forragem de neem, com o intuito de fornecer carboidratos solúveis para o processo fermentativo, promoveu uma diminuição da $M S(P<0,01)$ aos 28 dias de armazenamento $\left(39,32 \mathrm{~g} \cdot 100^{-1}\right)$, em relação aos $100 \%$ de neem $\left(39,52 \mathrm{~g} \cdot 100^{-1}\right)$, e aos 35 dias de armazenamento $\left(34,93 \mathrm{~g} \cdot 100^{-1}\right)$, quando comparado aos níveis de substituição de $50 \%$ de neem $(36,49$ g.100-1), $75 \%$ de neem $(37,93$ g.100-1) e $100 \%$ de neem $(43,15$ g.100-1 $)$.

Quando houve a substituição de $100 \%$ de neem (100N) aos 35 dias de armazenamento, a silagem apresentou $43,15 \%$ de MS e silagens que apresentam um teor de matéria seca superior a $40 \%$ podem apresentar baixa qualidade nutricional ao longo do tempo ou durante a utilização dos silos, pois são mais susceptíveis a danos por aquecimento e aparecimento de fungos (Van Soest, 1994).

O teor de proteína bruta (PB) das silagens confeccionadas (Tabela 3) aumentou de acordo com o aumento do nível de substituição da forragem de sorgo pelo neem $(P<0,01)$ e essa variação sofreu influência dos teores de proteína bruta das matérias-primas, como pode ser observado na Tabela 1.

Tabela 3 - Teores de proteína bruta $\left(\mathrm{g} .100 \mathrm{~g}^{-1}\right)$ das silagens confeccionadas substituindo a forragem do sorgo pela do neem aos 28 e 35 dias de armazenamento

\begin{tabular}{|c|c|c|c|c|c|c|c|}
\hline \multirow{2}{*}{$\begin{array}{c}\text { Dias de } \\
\text { armazenamento }\end{array}$} & \multicolumn{6}{|c|}{ Níveis de substituição da forragem de sorgo pela do neem } & \multirow{2}{*}{ Médias } \\
\hline & $0 \%$ & $25 \%$ & $50 \%$ & $75 \%$ & $100 \%$ & $100 \%+M$ & \\
\hline 28 dias & $6,54 c A$ & $7,60 \mathrm{cB}$ & 9,59Ca & $12,05 \mathrm{bA}$ & $11,29 b B$ & $15,39 a A$ & 10,41 \\
\hline 35 dias & $5,84 \mathrm{dA}$ & $11,82 \mathrm{bA}$ & $9,52 c A$ & $13,72 b A$ & $16,40 \mathrm{aA}$ & $14,66 \mathrm{aA}$ & 11,99 \\
\hline Médias & 6,19 & 9,71 & 9,55 & 12,88 & 13,84 & 15,02 & \\
\hline CV (\%) & \multicolumn{6}{|c|}{9,91} & \\
\hline
\end{tabular}


*Médias seguidas pela mesma letra minúscula na linha e maiúscula na coluna não diferem entre si pelo teste de ScottKnott, a $1 \%$ de probabilidade

Legenda: $0 \%$ = silagem com $100 \%$ de sorgo e $0 \%$ de neem; $25 \%$ = silagem com $75 \%$ de sorgo e $25 \%$ de neem; $50 \%=$ silagem com $50 \%$ de sorgo e $50 \%$ de neem; $75 \%$ = silagem com $25 \%$ de sorgo e $75 \%$ de neem; $100 \%=$ silagem com $0 \%$ de sorgo e $100 \%$ de neem e $100 \%+M=$ silagem com $0 \%$ de sorgo e $100 \%$ de neem + melaço.

No presente estudo, houve diferença significativa $(P<0,05)$ entre os níveis de substituição, aos 28 dias de armazenamento, mostrando que a silagem com $100 \%$ de neem + melaço apresentou o melhor nível de proteína bruta $\left(15,39 \mathrm{~g} \cdot 100 \mathrm{~g}^{-1}\right)$, seguido pelos níveis de susbtituição de $75 \%$ $\left(12,05 \mathrm{~g} \cdot 100 \mathrm{~g}^{-1}\right)$ e $100 \%\left(11,29 \mathrm{~g} \cdot 100 \mathrm{~g}^{-1}\right)$ que não diferiram entre si $(P>0,01)$. Aos 35 dias de armazenameno observou-se comportamento semelhante ao que ocorreu aos 28 dias, com os níveis que tiveram maiores substituição demonstrando melhores teores de PB $\left(100 \%=16,40 \mathrm{~g} \cdot 100 \mathrm{~g}^{-1}\right.$ e $100 \%+$ melaço $\left.=14,66 \mathrm{~g} .100 \mathrm{~g}^{-1}\right)$ sem diferirem entre si $(P>0,01)$ e a silagem exclusiva de sorgo apresentando o menor valor para esse nutriente $\left(0 \%=5,84 \mathrm{~g} \cdot 100 \mathrm{~g}^{-1}\right)$.

Quando foi comparado cada nível de substituição em relação aos dias de armazenamento, observou-se que a substituição de $100 \%$ e $100 \%$ + melaço da forragem de sorgo pelo neem mostraram melhores valores de proteína quando armazenado por 35 dias $(P<0,05)$ e esse aspecto pode ser explicado devido o alto teor de PB na forragem, sendo 8,81\% e 11,68\%, respectivamente. Além disso, o pH tem influência direta nos teores de PB. Onde quanto maior a resistência a redução do $\mathrm{pH}$, maior será a proteólise, consequência natural do processo de ensilagem, convertendo proteina em peptídeos, podendo-se elevar também os néveis de FDA e lignina.

Cândido et al. (1999), estudando silagens de diferentes híbridos de sorgo, obtiveram valores entre 6,30 e 6,98g.100 $\mathrm{g}^{-1}$ de $\mathrm{PB}$, não detectando diferença significativa entre as silagens. Estudando a composição protéica de silagens de sorgo, milho e girassol, Mello e Nornberg (2004) encontraram valores de PB abaixo de 7\% para sorgo, o que também foi evidenciado nesse estudo, o que pode ser explicado em função da baixa contribuição de panículas na massa ensilada. Moraes et al. (2013), ao estudarem silagens produzidas a partir de quatro híbridos de sorgo, encontraram valores de PB que variaram de 8,27 a 9,84\%, que de forma geral são inferiores aos encontrados nesse estudo para os níveis de substituição.

Dentre os níveis e os dias de armazenamentos estudados, apenas o nível onde não foi substituído o sorgo pelo neem (0\%) aos 35 dias de armazenamento não apresentou os teores mínimos de PB exigidos que, segundo Keplin e Santos (1996), esses valores devem estar entre 7,1\% a $8,0 \%$. Os teores de proteína na dieta podem influenciar o desenvolvimento dos animais, aumentando o consumo de matéria seca e melhorando a conversão alimentar e o ganho de peso (Zundt et al., 2002), por isso é importante a manutenção dos níveis mínimos adequados na alimentação dos animais.

Com relação aos níveis de fibra insolúvel em detergente neutro (FDN) (Tabela 4), percebese que a medida que se substituiu a forragem de sorgo pelo neem, houve decréscimo em seus teores. Os níveis de substituição mais satisfatórios foram encontrados nos níveis de $50 \%$ $\left(50,17 \mathrm{~g} \cdot 100 \mathrm{~g}^{-1}\right), 75 \%\left(49,15 \mathrm{~g} \cdot 100 \mathrm{~g}^{-1}\right), 100 \%$ de neem $\left(49,34 \mathrm{~g} \cdot 100 \mathrm{~g}^{-1}\right)$ e $100 \%$ neem + melaço $\left(46,69 \mathrm{~g} \cdot 100 \mathrm{~g}^{-1}\right)$, aos 28 dias de armazenamento, que não diferiram estatisticamente $(P<0,01)$. Aos 35 dias de armazenamento o nível que apresentou melhor teor de FDN $(P<0,01)$ foi o de $100 \%$ de 
substituição do sorgo com a adição de melaço $\left(45,07 \mathrm{~g} \cdot 100 \mathrm{~g}^{-1}\right)$, seguido pelos níveis de $75 \%$ $\left(49,67 \mathrm{~g} \cdot 100 \mathrm{~g}^{-1}\right)$ e $100 \%$ de neem $\left(49,88 \mathrm{~g} \cdot 100 \mathrm{~g}^{-1}\right)$ que não diferiram estatisticamente entre si $(P>0,05)$.

Tabela 4: Teores de fibra em detergente neutro $\left(\mathrm{g} \cdot 100 \mathrm{~g}^{-1}\right)$ das silagens confeccionadas substituindo a forragem do sorgo pela do neem aos 28 e 35 dias de armazenamento.

\begin{tabular}{cccccccc}
\hline \multirow{2}{*}{ Dias de armazenamento Níveis de substituição da forragem de sorgo pela do nem } & \multirow{2}{*}{ Médias } \\
\cline { 2 - 6 } & $0 \%$ & $25 \%$ & $50 \%$ & $75 \%$ & $100 \%$ & $100 \%+\mathrm{M}$ & \\
\hline 28 dias & $68,81 \mathrm{cA}$ & $54,50 \mathrm{bA}$ & $50,17 \mathrm{aA}$ & $49,15 \mathrm{aA}$ & $49,34 \mathrm{aA}$ & $46,69 \mathrm{aA}$ & 53,08 \\
35 dias & $68,46 \mathrm{dA}$ & $57,77 \mathrm{cA}$ & $54,53 \mathrm{cB}$ & $49,67 \mathrm{bA}$ & $49,88 \mathrm{bA}$ & $45,07 \mathrm{aA}$ & 54,23 \\
\hline Médias & 68,53 & 56,13 & 52,35 & 49,41 & 49,61 & 45,88 & \\
\hline CV (\%) & \multicolumn{7}{c}{3,49} \\
\hline
\end{tabular}

*Médias seguidas pela mesma letra minúscula na linha e maiúscula na coluna não diferem entre si pelo teste de ScottKnott, a $1 \%$ de probabilidade

Legenda: $0 \%$ = silagem com $100 \%$ de sorgo e $0 \%$ de neem; $25 \%=$ silagem com $75 \%$ de sorgo e $25 \%$ de neem; $50 \%=$ silagem com $50 \%$ de sorgo e $50 \%$ de neem; $75 \%$ = silagem com $25 \%$ de sorgo e $75 \%$ de neem; $100 \%=$ silagem com $0 \%$ de sorgo e $100 \%$ de neem e $100 \%+M=$ silagem com $0 \%$ de sorgo e $100 \%$ de neem + melaço.

Estes valores estão adequados ao padrão mencionado por Cruz et al. (2001), que afirmam que valores de FDN inferiores a $50 \mathrm{~g} \cdot 100 \mathrm{~g}^{-1}$ são mais desejáveis, uma vez que o consumo da silagem é inversamente relacionado ao conteúdo de FDN. Portanto, quanto menor o seu teor, maior é a degradabilidade da silagem e o consumo voluntário.

Cavalcante (2010) afirma que os teores de FDN acima de $55 \mathrm{~g} .100 \mathrm{~g}^{-1}$ limita o consumo pelos animais, devido ao efeito de saciedade física, fator que dá um efeito negativo na silagem. Valores superiores aos recomendados pelo autor foram observados nas silagens onde não houve a substituição do sorgo $\left(68,81 \mathrm{~g} \cdot 100 \mathrm{~g}^{-1}\right.$ - 28 dias e $68,46 \mathrm{~g} \cdot 100 \mathrm{~g}^{-1}$ - 35 dias), independentemente do tempo de armazenamento, e na silagem com $25 \%$ de substituição pelo neem aos 35 dias de armazenamento $\left(57,77 \mathrm{~g} \cdot 100 \mathrm{~g}^{-1}\right)$.

Analisando o tempos de armazenamento em função dos níveis de substituição da forragem de sorgo pelo neem, pode-se perceber que o único nível de substituição que diferiu estatísticamente $(P<0,01)$ em função do armazenamento foi o que substituiu $50 \%$, demonstrando um aumento dos teores de FDNi aos 35 dias $\left(54,53 \mathrm{~g} \cdot 100 \mathrm{~g}^{-1}\right)$ em relação aos 28 dias de armazenamento $(50,17 \mathrm{~g} \cdot 100 \mathrm{~g}$ 1).

Avaliando os teores de fibra insolúvel em detergente ácido (FDA) pode-se perceber que o seu teor, aos 28 dias de armazenamento, é menor nas silagens nas quais houve a substituição do sorgo pelo neem (Tabela 5). O comportamento apresentado pelas silagens contendo o neem, aos 28 dias de armazenamento, mostrou que a silagem com $50 \%$ de substituição de neem $(38,18 \mathrm{~g} \cdot 100 \mathrm{~g}$ ${ }^{1}$ ) e a exclusiva de neem com melaço $\left(35,18 \mathrm{~g} \cdot 100 \mathrm{~g}^{-1}\right)$ foram as que apresentaram os melhores níveis de FDA, sem diferem estatisticamente entre si $(P>0,01)$, demonstrando serem as mais digestíveis. Comportamento que não foi observado quando se abriu os silos aos 35 dias de armazenamento, pois não houve diferenças significativas $(P>0,01)$ em função dos níveis de substituição do sorgo pelo neem. 
Tabela 5: Teores de fibra em detergente ácido (g.100g. ${ }^{-1}$ ) das silagens confeccionadas substituindo a forragem do sorgo pela do neem aos 28 e 35 dias de armazenamento

\begin{tabular}{|c|c|c|c|c|c|c|c|}
\hline \multirow{2}{*}{$\begin{array}{c}\text { Dias de } \\
\text { armazenamento }\end{array}$} & \multicolumn{6}{|c|}{ Níveis de substituição da forragem de sorgo pela do neem } & \multirow[t]{2}{*}{ Médias } \\
\hline & $0 \%$ & $25 \%$ & $50 \%$ & $75 \%$ & $100 \%$ & $100 \%+M$ & \\
\hline 28 dias & $44,62 \mathrm{cA}$ & $40,26 \mathrm{Ba}$ & $38,18 \mathrm{aA}$ & $41,03 \mathrm{bA}$ & $40,63 \mathrm{bA}$ & $35,18 \mathrm{aA}$ & 39,98 \\
\hline 35 dias & $42,99 a A$ & $41,14 a A$ & $40,97 a A$ & $40,03 a A$ & $41,94 a A$ & $40,22 \mathrm{aB}$ & 41,21 \\
\hline Médias & 43,81 & 40,70 & 39,57 & 40,53 & 41,29 & 37,70 & \\
\hline CV (\%) & \multicolumn{6}{|c|}{3,73} & \\
\hline
\end{tabular}

*Médias seguidas pela mesma letra minúscula na linha e maiúscula na coluna não diferem entre si pelo teste de Scott-Knott, a $1 \%$ de probabilidade

Legenda: $0 \%$ = silagem com $100 \%$ de sorgo e $0 \%$ de neem; $25 \%$ = silagem com $75 \%$ de sorgo e $25 \%$ de neem; $50 \%$ = silagem com $50 \%$ de sorgo e $50 \%$ de neem; $75 \%$ = silagem com $25 \%$ de sorgo e $75 \%$ de neem; $100 \%=$ silagem com $0 \%$ de sorgo e $100 \%$ de neem e $100 \%+M=$ silagem com $0 \%$ de sorgo e $100 \%$ de neem + melaço.

Ao se comparar os tempos de armazenamento dentro dos mesmos níveis de substituição, observa-se, que apenas a silagem que continham $100 \%$ de neem associadas ao melaço apresentaram diferença significativa $(P<0,01)$, com a abertura dos silos aos 28 dias proporcionando melhores níveis de FDA (Tabela 5).

De maneira geral, com exceção da silagem exclusiva de sorgo aos 28 dias de armazenamento, as silagens apresentaram valores de FDA próximos aos encontrados para a silagem exclusiva de sorgo, como reportado por Viana et al. (2012), que mencionam que os valores de FDA para silagem de sorgo forrageiro devem ser próximos a $40 \%$ da MS. Esse resultado indica que a substituição da forragem de sorgo pela do neem não promoveu aumento desse componente nas silagens, o que podia prejudicar o desempenho dos animais

Conforme dispõem Oliveira et al. (2008), a alta porcentagem de FDA indica a presença de substâncias pouco aproveitáveis pelo animal, como lignocelulose, que são boas como indicadoras da má qualidade da silagem, pois apresentam correlação negativa com a digestibilidade da matéria seca.

Analisando os resultados obtidos sobre os teores de lignina presentes nas silagens (Tabela 6), percebe-se que, aos 28 dias de armazenamento, os níveis de substituição do sorgo pelo neem não apresentaram diferenças estatísticas entre si $(P>0,01)$, exceto para o nivel de $0 \%$ de substituição $\left(6,16 \mathrm{~g} \cdot 100 \mathrm{~g}^{-1}\right)$.

Tabela 6: Teores de lignina $\left(\mathrm{g} .100 \mathrm{~g}^{-1}\right)$ das silagens confeccionadas substituindo a forragem do sorgo pela do neem aos 28 e 35 dias de armazenamento

Dias de Níveis de substituição da forragem de sorgo pela do neem

\begin{tabular}{|c|c|c|c|c|c|c|c|}
\hline \multirow{2}{*}{$\begin{array}{l}\text { Dlas de } \\
\text { armazenamento }\end{array}$} & \multicolumn{6}{|c|}{ 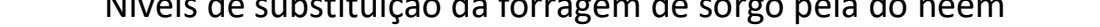 } & \multirow{2}{*}{ Médias } \\
\hline & $0 \%$ & $25 \%$ & $50 \%$ & $75 \%$ & $100 \%$ & $100 \%+M$ & \\
\hline 28 dias & $6,16 a A$ & $16,98 \mathrm{bA}$ & $17,00 \mathrm{bA}$ & $19,48 b A$ & $22,06 \mathrm{bA}$ & $21,20 \mathrm{bB}$ & 17,14 \\
\hline 35 dias & $7,05 \mathrm{aA}$ & $12,70 \mathrm{aA}$ & $17,90 \mathrm{bA}$ & $21,90 \mathrm{bA}$ & $19,07 \mathrm{bA}$ & $12,93 a A$ & 15,26 \\
\hline Médias & 6,60 & 14,84 & 17,45 & 20,69 & 20,56 & 17,06 & \\
\hline
\end{tabular}

*Médias seguidas pela mesma letra minúscula na linha e maiúscula na coluna não diferem entre si pelo teste de Scott-Knott, a $1 \%$ de probabilidade

Legenda: $0 \%$ = silagem com $100 \%$ de sorgo e $0 \%$ de neem; $25 \%=$ silagem com $75 \%$ de sorgo e $25 \%$ de neem; $50 \%=$ silagem com $50 \%$ de sorgo e $50 \%$ de neem; $75 \%$ = silagem com $25 \%$ de sorgo e $75 \%$ de neem; $100 \%=$ silagem com $0 \%$ de sorgo e $100 \%$ de neem e $100 \%+M=$ silagem com $0 \%$ de sorgo e $100 \%$ de neem + melaço. 
Aos 35 dias de armazenamento, as melhores silagens foram as que continham apenas sorgo $\left(7,05 \mathrm{~g} \cdot 100 \mathrm{~g}^{-1}\right), 25 \%$ de neem $\left(12,70 \mathrm{~g} \cdot 100 \mathrm{~g}^{-1}\right)$ e a silagem com $100 \%$ de neem associada ao melaço $\left(12,93 \mathrm{~g} \cdot 100 \mathrm{~g}^{-1}\right)$ que diferiram dos demais níveis de substituição $(\mathrm{P}<0,01)$, contudo, não diferiram entre si $(P>0,01)$.

Esse aumento da lignina, com a presença do neem, pode estar associado a presença dos pecíolos na composição das silagens, que se apresentam mais lignificados do que as folhas, como pode ser observado na Tabela 1, onde está representada a composição das matérias-primas antes da ensilagem. Quando se compara os tempos de armazenamento, verifica-se que só houve diferença estatística $(P<0,01)$ nos níveis com neem associado ao melaço, sendo os melhores valores obtidos com 35 dias de armazenamento (12,93 g.100g-1) em comparação aos 28 dias (21,2 g.100g$\left.{ }^{1}\right)$.

A lignina é a parte da fibra presente no alimento em que o animal não digere, então, os seus teores quando estão elevados comprometerão a digestibilidade do alimento, uma vez que impede a ação dos micro-organismos do rúmen (Van Soest, 1994). Os altos teores de lignina dificultam o consumo de forragem por parte dos animais e afetam negativamente a produtividade animal, uma vez que altas concentrações tornam mais lenta à passagem do volumoso pelo rúmen (Agrolink, 2010).

Martins et al. (2003), citam que os níveis inferiores a 7,3\% de lignina nas silagens favorecem o aumento do consumo e da digestibilidade das frações fibrosas. Levando em consideração essa informação, observa-se que as únicas silagens que atenderam a essa exigência foram às silagens exclusivas de sorgo, independentemente do tempo de armazenamento, assim como as silagens com substituição de $25 \%$ de neem e $100 \%$ neem com melaço, aos 35 dias de armazenamento.

As temperaturas das silagens foram influenciadas $(P<0,01)$ pelo nível de substituição de sorgo pelo neem aos 28 e aos 35 dias de armazenamento. Aos 28 dias de armazenamento, as silagens sofreram aumentos da sua temperatura à medida que se aumentou o percentual de neem, o que possivelmente pode estar relacionado aos altos teores de MS que, consequentemente, podem ter prolongado a estabilização do processo fermentativo. Aos 35 dias de armazenamento percebe-se uma maior uniformidade entre as temperaturas obtidas entre os níveis de substituição,embora tenha havido diferença estatística $(P<0,01)$, sendo a maior temperatura observada quando se substituiu $75 \%$ da forragem de sorgo pelo neem $\left(31,20^{\circ} \mathrm{C}\right)$ e as menores temperaturas detectadas nas silagens com $0 \%\left(28,42{ }^{\circ} \mathrm{C}\right)$ e $50 \%\left(28,83^{\circ} \mathrm{C}\right)$ de substituição.

Tabela 7: Temperaturas $\left({ }^{\circ} \mathrm{C}\right)$ das silagens confeccionadas substituindo a forragem do sorgo pela do neem aos 28 e 35 dias de armazenamento

\begin{tabular}{cccccccc}
\hline Dias de & \multicolumn{9}{c}{ Níveis de substituição da forragem de sorgo pela do nem } & \multirow{2}{*}{ Médias } \\
\cline { 2 - 6 } armazenamento & $0 \%$ & $25 \%$ & $50 \%$ & $75 \%$ & $100 \%$ & $100 \%+\mathrm{M}$ & \\
\hline 28 dias & $30,51 \mathrm{aB}$ & $30,80 \mathrm{bB}$ & $30,98 \mathrm{cB}$ & $31,42 \mathrm{dA}$ & $32,02 \mathrm{eB}$ & $32,50 \mathrm{fB}$ & 31,37 \\
35 dias & $28,42 \mathrm{aA}$ & $29,25 \mathrm{bA}$ & $28,83 \mathrm{aA}$ & $31,20 \mathrm{cA}$ & $30,00 \mathrm{bA}$ & $29,50 \mathrm{bA}$ & 29,53 \\
\hline Médias & 29,47 & 30,30 & 29,91 & 30,98 & 31,01 & 31,00 & \\
\hline CV (\%) & \multicolumn{7}{c}{0,29} \\
\hline
\end{tabular}

*Médias seguidas pela mesma letra minúscula na linha e maiúscula na coluna não diferem entre si pelo teste de ScottKnott, a $1 \%$ de probabilidade 
Legenda: $0 \%$ = silagem com $100 \%$ de sorgo e $0 \%$ de neem; $25 \%=$ silagem com $75 \%$ de sorgo e $25 \%$ de neem; $50 \%=$ silagem com $50 \%$ de sorgo e $50 \%$ de neem; $75 \%$ = silagem com $25 \%$ de sorgo e $75 \%$ de neem; $100 \%=$ silagem com $0 \%$ de sorgo e $100 \%$ de neem e $100 \%+M=$ silagem com $0 \%$ de sorgo e $100 \%$ de neem + melaço.

Comparando a significância entre os dias de armazenamento nos mesmos níveis de substituição, apenas o nível de $75 \%$ de neem não diferiu estatisticamente $(P>0,01)$. Todos os outros níveis apresentaram diferenças estatísticas $(P<0,01)$, comprovando que o teor de neem na ensilagem ocasiona diferença de temperatura quanto aos dias de armazenamento. As temperaturas mais elevadas observadas com 28 dias de armazenamento, em relação ao 35 dias, demonstra que nesse período, ainda, havia processos fermentativos e que as silagens não estavam adequadas para serem abertas. Essa atividade fermentativa pode ser comprovada pelo fato das temperaturas, aos 35 dias de armazenamento, terem diminuido, indicando, provavelmente, que a fermentação tinha cessado e as silagens estavam estabilizadas.

$\mathrm{O}$ pH das silagens, considerado um parâmetro físico importante e necessário para o processo fermentativo (MACEDO et al., 2012), estão representados na Tabela 8. Foram observadas diferenças significativas $(P<0,01)$ entre as silagens com níveis diferentes de substituição da forragem de sorgo pelo neem, tanto nas que foram armazenadas por 28 dias, quanto nas que ficaram vedadas por 35 dias, com aumento no $\mathrm{pH}$ pela maior presença do neem.

Ao se comparar cada nível de substituição em função dos dias de armazenamento, observase que a única silagem que apresentou diferenças significativas $(p<0,01)$ de $\mathrm{pH}$ entre os dias de abertura foi a que foi produzida exclusivamente com neem, demonstrando uma queda de $\mathrm{pH}$ do patamar de 5,11 na silagem armazenada por 28 dias, para 4,78 na silagem aberta após 35 dias de armazenamento. Esse resultado evidencia que aos 28 dias o neem armazenado não estava com o seu processo fermentativo concluído, sendo necessário mais tempo entre o processo de confecção da silagem e a abertura do silo para fornecimento aos animais.

Tabela 8: pH das silagens confeccionadas substituindo a forragem do sorgo pela do neem aos 28 e 35 dias de armazenamento

\begin{tabular}{|c|c|c|c|c|c|c|c|}
\hline \multirow{2}{*}{$\begin{array}{c}\text { Dias de } \\
\text { armazenamento }\end{array}$} & \multicolumn{6}{|c|}{ Níveis de substituição da forragem de sorgo pela do nem } & \multirow{2}{*}{ Médias } \\
\hline & $0 \%$ & $25 \%$ & $50 \%$ & $75 \%$ & $100 \%$ & $100 \%+M$ & \\
\hline 28 dias & $3,49 a A$ & $3,62 \mathrm{aA}$ & $3,87 \mathrm{bA}$ & $4,27 c A$ & $5,11 \mathrm{dA}$ & $4,20 c A$ & 4,09 \\
\hline 35 dias & $3,52 \mathrm{aA}$ & $3,74 a A$ & 3,97Ba & $4,19 \mathrm{cA}$ & $4,78 c B$ & $4,10 c A$ & 4,05 \\
\hline Médias & 3,51 & 3,92 & 3,92 & 4,23 & 4,95 & 4,15 & \\
\hline
\end{tabular}

*Médias seguidas pela mesma letra minúscula na linha e maiúscula na coluna não diferem entre si pelo teste de ScottKnott, a $1 \%$ de probabilidade

Legenda: $0 \%=$ silagem com $100 \%$ de sorgo e $0 \%$ de neem; $25 \%=$ silagem com $75 \%$ de sorgo e $25 \%$ de neem; $50 \%=$ silagem com $50 \%$ de sorgo e $50 \%$ de neem; $75 \%$ = silagem com $25 \%$ de sorgo e $75 \%$ de neem; $100 \%=$ silagem com $0 \%$ de sorgo e $100 \%$ de neem e $100 \%+M=$ silagem com $0 \%$ de sorgo e $100 \%$ de neem + melaço.

Silagens bem preservadas, segundo França et al. (2011), devem apresentar um pH na faixa de 3,7 a 4,2, enquanto as de baixa qualidade se situam entre 5,0 a 7,0. Diante desse contexto, a única silagem que não pode ser considerada de boa qualidade foi a confeccionada exclusivamente com neem, pois apresentou resultados superiores aos considerados adequados para uma boa silagem, o que possivelmente pode ser explicado pela falta de umidade para que os microrganismos pudessem atuar, já que o teor de MS em 100\% neem foi elevado. Além disso, o neem pode ter atuado de forma 
direta contra a ação microbiana, o que dificultaria o estabelecimento da mesma, consequente fermentação e redução do pH.

É importante frisar que não há estudos fazendo uso do neem para confecção de alimentos conservados, ficando difícil a realização de comparação de dados. Apesar de tal escassez, observase que os dados de temperatura e de $\mathrm{pH}$ obtidos neste estudo, estão de acordo com os recomendados na literatura, como os encontrados por Ribeiro et al. (2007), ao avaliarem quatro genótipos diferentes de Sorgo, que verificaram pH satisfatório para o padrão de fermentação, e aos relatados por Araújo et al. (2007), que ao trabalharem com silagem de Sorgo obtiveram, em estádio de grãos farináceos, valores de pH entre 3,9 e 4,07.

\section{CONCLUSÃO}

A substituição da forragem de sorgo pelo neem deve ser realizada até o nível de $25 \%$ ou pode-se ensilar exclusivamente o neem associado ao melaço, em que a silagem de ambos só deverá ser utilizada após 35 dias de armazenamento, uma vez que a composição química foi considerada satisfatória, configurando-se como uma alternativa que pode ser usada na alimentação dos ruminantes.

\section{REFERÊNCIAS BIBLIOGRÁFICAS}

Adjorlolo, L. K., Timpong-Jones, E. C., Boadu, S., \& Adogla-Bessa, T. (2016). Potential contribution of neem (Azadirachta indica) leaves to dry season feeding of ruminants in West Africa. Livestock Research for Rural Development. 28(5).

Agrolink. Sorgo com menor teor de lignina permite ganhos em produção de carne e leite. (2010). Recuperado de: <https://www.agrolink.com.br/noticias/sorgo-com-menor-teor-de-ligninapermite-ganhos-em-producao-de-carne-e-leite_106896.html>.

Araújo, V.L., Rodriguez, N.M., Gonçalves, L.C., Rodrigues, J.A.S., Borges, I., Borges, A.L.C.C., \& Saliba, E.O.S.. (2007). Qualidade das silagens de três híbridos de sorgo ensilados em cinco diferentes estádios de maturação. Arquivo Brasileiro de Medicina Veterinária e Zootecnia, 59(1), 168-174. https://doi.org/10.1590/S0102-09352007000100028

Atangwho, I. J., Ebong, P. E., Eyong, E. U., Williams, I. O., Eteng, M. U., \& Egbung, G E. (2009). Comparative chemical composition of leaves of some antidiabetic medicinal plants: Azadirachta indica, Vernonia amygdalina and Gongronema latifolium. African Journal of Biotechnology, (8), 4685-4689.

Azevedo, G. T. O. S., Novaes, A. B., Azevedo, G. B., \& Silva, H. F. (2015). Desenvolvimento de Mudas de Nim Indiano sob Diferentes Níveis de Sombreamento. Floresta e Ambiente, 22(2), 249-255.

Borba, L. F. P., Ferreira, M. de A., Guim, A., Tabosa, J. N., Gomes, L. H. dos S., \& Santos, V. L. F. dos. (2012). Nutritive value of diferents silage sorghum (Sorghum bicolor L. Moench) cultivares. Acta Scientiarum.

Animal Sciences,

$34(2)$, 123-129. https://doi.org/10.4025/actascianimsci.v34i2.12853 
Cândido, M.J.D.; Obeid, J.A.; Pereira, O.G. et al. (1999). Avaliação da produção e do valor nutritivo de silagens de cinco híbridos de sorgo 1. FOR:056. Anais da Reunião Anual da Sociedade Brasileira de Zootecnia, 36, Viçosa, MG, Brasil.

Cavalcante, D. R. (2010). Valor nutricional do milho, milheto e sorgo, desempenho animal e composição devacas mestiças leiteiras (Dissertação de Mestrado). Universidade Federal de Uberlândia. Uberlândia, MG, Brasil.

Cruz, J.C.; Pereira Filho, I.A.; \& Rodrigues, J. A. S. (2001). Produção e utilização de silagem de milho e sorgo. Sete Lagoas: Embrapa Milho e Sorgo.

Elias, O. F. A. S., Leite, M.L.M.V., Azevedo, J. M., Silva, J. P. S. S., Nascimento, G. F., \& Simplício, J. B. (2016). Características agronômicas de cultivares de sorgo em sistema de plantio direto no semiárido de Pernambuco. Ciência Agrícola, 14(1), 29-36.

Fonseca, R. S., Oliveira, A. F. M., Martinhs, I. V. F., Donatele, D. M., Oliveira, F. A., Vidal, M. L. B., Moulin, I. R. M., \& Quirino, C. R. (2019). Efeitos da torta de neem no controle alternativo de nematoides gastrintestinais em ovinos: Revisão. PUBVET, 13(4), 1-12.

França, A. F. D. S., Oliveira, R. D. P., Miyagi, E. S., Da Silva, A. G., Perón, H. J. M. C., \& Basto, D. D. C. (2011). Características fermentativas da silagem de híbridos de sorgo sob doses de nitrogênio. Ciência Animal Brasileira, 12(3), 383-391. Recuperado de https://www.revistas.ufg.br/vet/article/view/540

Greenhill, W. L. (1964). Plant juice in relation to silage fermentation. I - The role of the juice. Journal of the British Grassland Society, 19, 30-37.

Jobim, C. C., Nussio, L. G., Reis, R. A., \& Schmidt, P. (2007). Avanços metodológicos na avaliação da qualidade da forragem conservada. Revista Brasileira de Zootecnia, 36(Supl. ), 101-119. https://dx.doi.org/10.1590/S1516-35982007001000013

Keplin, L. da A. S., \& Santos, I. R dos. (1996). Silagem de milho. Campinas: Fundação ABC.

Lima, J. A.; Silagem de Sorgo. (2006). São Paulo: Instituto de Zootecnia (IZ-APTA).

Lima-Orozco, R., Castro-Alegría, A., \& Fievez, V. (2013). Ensiled sorghum and soybean as ruminant feed in the tropics, with emphasis on Cuba. Grass and Forage Science, 68(1).

Macedo, C. H. O., Andrade, A. P. de, Santos, E. M., Silva, D. S. da, Silva, T. C. da, \& Edvan, R. L. (2012). Perfil fermentativo e composição bromatológica de silagens de sorgo em função da adubação nitrogenada. Revista Brasileira de Saúde e Produção Animal, 13(2), 371-382. https://doi.org/10.1590/S1519-99402012000200007

Martini, A. P. M., Brondani, I. L., Silva, V. S. da, Alves Filho, D. C., Martini, P. M., \& Argenta, F. M. (2019). Características morfogênicas e estruturais do sorgo forrageiro submetido a lotação contínua com novilhos de corte suplementados. Ciência Animal Brasileira, 20, e45172. Epub September 30, 2019.https://doi.org/10.1590/1089-6891v20e-45172 
Martins, R.G.R., Gonçalves, L.C., Rodrigues, J.A.S., Rodriguez, N.M., Borges, I., \& Borges, A.L.C.C.. (2003). Consumo e digestibilidade aparente das frações fibrosas de silagens de quatro genótipos de sorgo (Sorghum bicolor (L.) Moench) por ovinos. Arquivo Brasileiro de Medicina Veterinária e Zootecnia, 55(3), 346-349. https://doi.org/10.1590/S0102-09352003000300015

McDonald, P. (1981). The biochemistry of silage. New York: John Willey \& Sons.

McDonald, P., Henderson, A. R., \& Heron, S. (1991). The biochemistry of silage. 2.ed. Marlow: Chalcombe.

Mello, R., \& Nörnberg, J. L.. (2004). Fracionamento dos carboidratos e proteínas de silagens de milho, sorgo e girassol. Ciência Rural, 34(5), 1537-1542. https://doi.org/10.1590/S010384782004000500033

Mizubuti, I. Y. (2009). Métodos laboratoriais de avaliação de alimentos para animais. Londrina: EDUEL.

Moraes, S. D., Jobim, C. C., Silva, M. S., \& Marquardt, F.I. (2013). Produção e composição química de híbridos de sorgo e de milho para silagem. Revista Brasileira de Saúde e Produção Animal, 14 (4), 624-634.

Mossini, S. A. G., \& Kemmelmeier, C. (2005). A árvore Nim (Azadirachta indica A. Juss): Múltiplos Usos Simone Aparecida Galerani. Acta Farmaceutica Bonaerense, 24(1), 139-48.

Moura, M. M. A., Pires, D. A. De A., Rodrigues, J.A.S., Sales, E.C.J., Costa, R. F., \& Tolentino, D. C. (2016). Chemical composition of sorghum genotypes silages. Acta Scientiarum. Animal Sciences, 38 (4), 369-373. https://doi.org/10.4025/actascianimsci.v38i4.31810

Muck, R.E., Bolsen, K.K. (1991) Silage preservation and silage additive products. In FieldGuide for Hay and Silage Management in North America. (pp. 105-126). NFIA.

Musalia, L. M., Anadan, S., Sastry, V. R. B. (2000). Urea-treated neem (Azadirachta indica A. juss) seed kernel cake as a protein supplement for lambs. Small Ruminant Research, 35(2), 107-16.

Neumann, M.; Restle, J.; \& Brondani, I. L. (2004). Avaliação de silagens de sorgo (Sorghum bicolor, I. moench) ou milho (zea mays, I.) na produção do novilho superprecoce Revista Brasileira de Milho e Sorgo, 3(3), 438-452.

Oliveira, L. B. de., Pires, A. J. V., Carvalho, G. G. P. de., Ribeiro, L. S. O., Almeida, V. V. de., \& Peixoto, C. A. de M. (2010). Perdas e valor nutritivo de silagens de milho, sorgo-sudão, sorgo forrageiro e girassol. Revista Brasileira de Zootecnia, 39(1), 61-67. https://dx.doi.org/10.1590/S1516$\underline{35982010000100008}$

Pinho, R. G. V., Vasconcelos, R.C.de., Borjes, I.D., \& Rezende, A.V. (2006). Influência da altura de corte das plantas nas características agronômicas e valor nutritivo das silagens de milho e de diferentes tipos de sorgo. Revista Brasileira de Milho e Sorgo, 5(2), 266-279.

Ribeiro, C.G.M., Gonçalves, L.C., Rodrigues, J.A.S, Rodriguez, N.M., Borges, I., Borges, A.L.C.C., Saliba, E.O.S., Castro, G.H.F., \& Ribeiro Junior, G.O.. (2007). Padrão de fermentação da silagem de cinco 
genótipos de sorgo. Arquivo Brasileiro de Medicina Veterinária e Zootecnia, 59(6), 1531-1537. https://doi.org/10.1590/S0102-09352007000600028

Santos, R. F., Placido, H. F, Garcia, E. B., Cantú, C., Albrecht, A. J. P., Albrecht, L. P., \& Frigo, K. D. A. (2015). Sorgo sacarino na produção de agroenergia. Revista Brasileira de Energias Renováveis, 4, 01- 12.

Silva, D. J., \& Queiroz, A. C. (2002). Análise de Alimentos: métodos químicos e biológicos. Viçosa: UFV.

SILVA, D. J.; QUEIROZ, A. C. (2009). Análise de alimentos: métodos químicos e biológicos. 3. ed. Viçosa: UFV.

Siqueira, G. R., Reis, R. A., Schocken-Iturrino, R. P., Pires, A. J. V., Bernades, T. F., \& Amaral, R. C. do. (2007). Perdas de silagens de cana-de-açúcar tratadas com aditivos químicos e bacterianos. $R$. Bras. Zootec., 36, (6), 2000-2009.

Soares Filho, C. V., Rosa, P. R. B., Costa, R. L. D., \& Espada, J. C. P. (2015). Óleo de neem (Azadirachta indica) nos parâmetros parasitológicos, hematológicos e bioquímicos de ovinos naturalmente infectados por nematoides gastrintestinais. Revista Brasileira Saúde Produção Animal, 16(2), 408-419.

Stella L. A., Peripolli, V., Prates, E. R., Barcellos, J. O. J. (2016). Composição química das silagens de milho e sorgo com inclusão de planta inteira de soja. Boletim da Indústria Animal, 73, (1), 7379.

Van Soest, P. J. (1994). Nutritional ecology of ruminant. Ithaca: Comstock Publishing Associations.

Viana, P. T., Pires, A. J. V., Oliveira, L. B., Carvalho, G. G. P., Ribeiro, L. S. O., Chagas, D. M. T., Nascimento Filho, C. S., \& Carvalho, A. O. (2012). Fracionamento de carboidratos e de proteína das silagens de diferentes forrageiras. Revista Brasileira de Zootecnia, 41(2), 292-297.

Zundt, M.; Macedo, F. A. F.; Martins, E. N. (2002). Desempenho de cordeiros alimentados com diferentes níveis protéicos. Revista Brasileira de Zootecnia, 31(3), 1307-1314.

\section{COMO CITAR ESTE ARTIGO:}

Soares, M. M. de F., Souza, C. M. S. de., Rodrigues, B. N., Terceiro, F. da C. R., Barreto, H. F. M., Jesus, P. P. C. de. (2020). Padrão de qualidade da silagem de sorgo (Sorghum bicolor L. Moench) associado ao neem (Azadirachta indica). Holos. 36(6), 1-16.

\section{SOBRE OS AUTORES}

\section{M. DE F. SOARES}

Zootecnista formada pela UFERSA e mestranda no Programa de Produção Animal na UFERSA.

E-mail: marianafreittas@outlook.com.br

ORCID ID: https://orcid.org/0000-0003-2693-2976

\section{M. S. DE SOUZA}

Zootecnista, doutora em Zootecnia pela UFPB e Docente do IFRN - Campus Apodi.

E-mail: cicilia.silva@ifrn.edu.br 
ORCID ID: https://orcid.org/0000-0002-5233-7575

\section{B. N. RODRIGUES}

Zootecnista formado pela UFERSA. E-mail: brenonoronhar@gmail.com ORCID ID: https://orcid.org/0000-0002-0557-2708

\section{F. DA C. R. TERCEIRO}

Cursando graduação em Zootecnia na UFERSA e Membro da Empresa Júnior de Zootecnia (EMJUZ).

E-mail: terceirozootec@hotmail.com

ORCID ID: https://orcid.org/0000-0003-3129-4921

\section{H. F. M. BARRETO}

Zootecnista, doutor em Ciência Animal pela UFERSA e docente no IFRN - Campus Apodi.

E-mail: felipebarreto.ifrn@gmail.com

ORCID ID: https://orcid.org/0000-0003-4556-4881

\section{P.P. C. DE JESUS}

Cursando graduação em Zootecnia na UFERSA e Membro da Empresa Júnior de Zootecnia (EMJUZ).

E-mail: paloma apodi@hotmail.com

ORCID ID: https://orcid.org/0000-0002-9124-8954

Editor(a) Responsável: Francinaide de Lima Silva Nascimento e Anísia Galvão

Pareceristas Ad Hoc: Emanuel Neto Oliveira e Arivonaldo da Silva

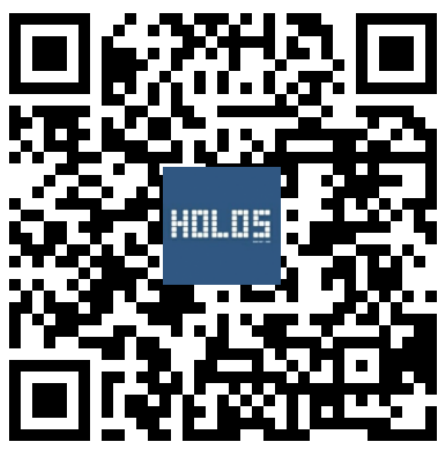

